\title{
Differential effect of adjuvant taxane-based and taxane-free chemotherapy regimens on the CK-19 mRNA-positive circulating tumour cells in patients with early breast cancer
}

\author{
N Xenidis ${ }^{1,2}$, M Perraki ${ }^{3}$, S Apostolaki ${ }^{3}$, S Agelaki ${ }^{1,3}$, K Kalbakis ${ }^{1}$, N Vardakis ${ }^{1}$, A Kalykaki ${ }^{1}$, A Xyrafas ${ }^{1}$, \\ S Kakolyris ${ }^{2}$, D Mavroudis ${ }^{1,3}$ and V Georgoulias ${ }^{\star 1,3}$ \\ ${ }^{1}$ Department of Medical Oncology, University Hospital of Heraklion, PO Box 1352, 71110 Heraklion, Crete, Greece; ${ }^{2}$ Department \\ of Medical Oncology, University Hospital of Alexandroupolis, Alexandroupolis, Greece and ${ }^{3}$ Laboratory of Tumor Cell Biology, \\ School of Medicine, University of Crete, Heraklion, Crete, Greece
}

Background: To determine the effect of adjuvant taxane-free and taxane-based chemotherapy regimens on the elimination of circulating tumour cells (CTCs) in patients with early breast cancer.

Methods: The presence of CK-19 mRNA-positive CTCs in the peripheral blood was evaluated before and after chemotherapy, using a real-time RT-PCR assay, in a historical comparison of two cohorts of women with stage I-III breast cancer treated with adjuvant taxane-free $\left(N=211 ; \mathrm{FE}_{75} \mathrm{C}\right.$ or $\left.\mathrm{E}_{75} \mathrm{C}\right)$ and taxane-based $\left(\mathrm{N}=334 ; \mathrm{T} / \mathrm{E}_{75} \mathrm{C}\right.$ or $\left.\mathrm{T} / \mathrm{E}_{75}\right)$ chemotherapy.

Results: Taxane-based chemotherapy resulted in a higher incidence of CTCs' elimination than taxane-free regimens since $49.7 \%$ (74 of 149) and 33.0\% (29 of 88) of patients with detectable CTCs before chemotherapy, respectively, turned negative postchemotherapy $(P=0.015)$. Patients treated with taxane-free regimens had a significantly lower disease-free survival (DFS) $(P=0.035)$ than patients treated with taxane-based regimens; this difference was observed in patients with but not without detectable CTCs before chemotherapy $(P=0.018$ and $P=0.481$, respectively). The incidence of deaths was significantly higher in the taxane-free cohort of patients with but not without detectable CTCs before chemotherapy compared with that of the taxanebased cohort $(P=0.002)$. Multivariate analysis revealed that the chemotherapy regimen was significantly associated with prolonged DFS (HR: 2.00; 95\% Cl=1.20-3.34).

Conclusion: Elimination of CK-19 mRNA-positive CTCs during adjuvant chemotherapy seems to be an efficacy indicator of treatment and is associated with a favourable clinical outcome of patients with detectable CTCs before chemotherapy.

The target of systemic adjuvant treatment is the elimination of the cells that escaped from primary tumour before or during its surgical excision. Consistent data have shown that adjuvant chemotherapy improves disease-free survival (DFS) and overall survival (OS) in breast cancer patients (Early Breast Cancer Trialists' Collaborative Group, 2005). Although the reduction of local or distant relapse rates is an absolute index of the efficacy of adjuvant treatment, there is no validated tool to monitor its effect (Bonadonna et al, 2005).

Circulating tumour cells (CTCs) and disseminated tumour cells (DTCs) have been studied in metastatic and early stage breast cancer. The detection of $>5$ CTCs per $7.5 \mathrm{ml}$ of blood before or at any time during therapy was associated with shorter median progression-free survival and OS in patients with metastatic breast 
cancer (Cristofanilli et al, 2004; Hayes et al, 2006); moreover, treatment-induced decrease to $<5$ CTCs per $7.5 \mathrm{ml}$ of blood 4 weeks after the initiation of chemotherapy was shown to be an earlier indicator of clinical response and to better correlate with OS than the standard imaging assessment (Budd et al, 2006; Liu et al, 2009). In addition, in patients with locally advanced disease the detection of CTCs after neoadjuvant chemotherapy is an independent prognostic factor for early relapse (Pierga et al, 2008), whereas the decrease in CTCs during the first cycle of neoadjuvant treatment predicts for a favourable tumour response (Camara et al, 2007).

Recently, it was reported that in patients with early breast cancer the relapse-free survival is proportional to the fluctuation of the absolute number of detected CTCs during adjuvant chemotherapy (Pachmann et al, 2008). In addition, we had shown that the persistence of CTCs after the completion of adjuvant chemotherapy is an independent prognostic factor associated with DFS and OS (Xenidis et al, 2009). The aim of the current study was to investigate the effect of adjuvant taxane-free and taxane-based chemotherapy regimens on the elimination of CK-19 mRNApositive CTCs $(\mathrm{CK}-19(+)$ cells) and its association with patients' clinical outcome.

\section{PATIENTS AND METHODS}

Patient population. In all, 545 women with operable (stage I-III) breast cancer were treated in the Department of Medical Oncology of the University General Hospital of Heraklion, Crete from September 1996 to November 2008. Most of these patients (almost $60 \%)$ were treated in the context of research protocols of the Hellenic Oncology Research Group (HORG) comparing taxanebased with taxane-free regimens in both node-positive and nodenegative disease. One of these trials has already been published (Polyzos et al, 2010), another (comparing dose dense FE75C followed by paclitaxel $v s$ FE75C followed by docetaxel in nodepositive patients) has been submitted for presentation in the upcoming SABCS 2012, whereas the two other studies (one in node-positive patients comparing dose dense docetaxel followed by FE75C vs docetaxel/cyclophosphamide and one in node-negative patients comparing docetaxel followed by epirubicin $v s$ docetaxel plus epirubicin) are not yet mature for final analysis. The remaining patients (almost $40 \%$ ) were treated out of protocol with FE75C or E75C chemotherapy. There were no patients treated with CMF. In the current study, only patients with available blood samples both before and after the completion of adjuvant chemotherapy were included. All patients had a complete diagnostic evaluation to exclude the presence of distant metastases. Of 545 patients, 392 were treated with lumpectomy and 153 with total mastectomy. Adjuvant radiotherapy was administered in 468 patients and all patients with hormone receptor-positive tumours were treated with either tamoxifen for 5 years or tamoxifen for 2-3 years followed by an aromatase inhibitor for an additional 2-3 years; premenopausal women also received luteinising hormonereleasing hormone analogues for $2-3$ years. Sixty (11\%) patients with HER-2/neu-positive tumours (immunohistochemical score of $3+$ or FISH positive), treated before the registration of trastuzumab in the adjuvant setting (2005), were included in the analysis since they did not receive trastuzumab. Patients with HER2/neu-positive disease who received trastuzumab were excluded from this analysis since we have previously shown that it can eliminate CK-19 mRNA-positive CTCs (Bozionellou et al, 2004). Patients' follow-up consisted of clinical examination with laboratory and imaging studies every 3 months for the first 2 years, every 6 months for the next 3 years and yearly thereafter. Patients signed an informed consent to participate in this biomarker study, which was approved by the Ethics and Scientific Committees of our Institution.

Blood samples and real-time RT-PCR assay for CK-19 mRNA $(+)$ CTCs. Peripheral blood (20 $\mathrm{ml}$ in EDTA) was obtained 3-4 weeks after primary surgery and before the initiation of adjuvant chemotherapy and within 3-4 weeks after the completion of adjuvant chemotherapy as previously reported (Stathopoulou et al, 2003; Xenidis et al, 2009). The procedures of RNA extraction and cDNA synthesis, the real-time RT-PCR assay for the detection of CK-19 mRNA-positive CTCs as well as its specificity and sensitivity have been previously reported in detail (Stathopoulou et al, 2003). According to the analytical detection limit of the assay, the presence of $\geqslant 0.6 \mathrm{MCF}-7$ equivalents $/ 5 \mu \mathrm{g}$ of total RNA was considered as a positive result.

Statistical analysis. This is a non-randomised, correlative and retrospective study conducted in patients with early breast cancer receiving both taxane-based and taxane-free chemotherapy regimens. Therefore, the study has not a specific statistical design and a sample size calculation. Differences between categorical variables were analysed by $\chi^{2}$ tests or Fisher's exact test. Disease-free survival was calculated from the time of study entry to the time of locoregional or distant relapse and OS from the time of study entry to the time of death from any cause. Survival curves were plotted according to the Kaplan-Meier method and compared using the log-rank test. Cox proportional-hazards regression analysis was used to estimate univariate and multivariate hazard ratios for DFS and OS. Clinicopathologic factors, known to be associated with prognosis, were tested in univariate analysis. Variables that were found to be significant at the univariate analysis were then entered in a stepwise multivariate Cox proportional hazards regression model to identify those with independent prognostic information. A proportional hazards model with treatment covariate (taxanefree $v s$ taxane-based regimen), CK-19 mRNA-positive CTCs status and their interaction was used to assess whether CTCs detection before chemotherapy was predictive of treatment efficacy. For all analyses, a $P$-value of $<0.05$ was considered to be statistically significant. SPSS version 15 statistical software (SPSS Inc., Chicago, IL, USA) was used for the analysis. This report was written in accordance with the REporting of tumour MARKer Studies recommendations (McShane et al, 2005).

\section{RESULTS}

Patient characteristics. In total, 211 (38.7\%) patients received a taxane-free and $334(61.3 \%)$ a taxane-based regimen as adjuvant chemotherapy (Table 1). Median patient age was 54.0 and 53.0 years in the taxane-free and the taxane-based groups, whereas 55\% and $52.4 \%$ were post-menopausal, respectively. The primary tumour was $\leqslant 2.0 \mathrm{~cm}$ in $34.6 \%$ and $34.1 \%$ patients treated with taxane-free and taxane-based regimens, respectively. In addition, $43.6 \%$ and $41.3 \%$ patients treated with a taxane-free and a taxanebased regimen had grade III tumours, whereas $68.3 \%$ and $68.8 \%$ of them, respectively, had involved axillary lymph nodes. ER-positive tumours had $65 \%$ and $64.8 \%$ patients treated with a taxane-free and a taxane-based regimen, respectively. HER-2/neu-positive tumours (immunohistochemical score of $3+$ or FISH + ) were detected in $13.1 \%$ and $10.1 \%$ patients treated with a taxane-free and a taxane-based regimen, respectively. In all, 88 (41.7\%) and $149(44.6 \%)$ patients treated with a taxane-free and a taxane-based regimen, respectively, had detectable CK-19 $(+)$ cells before chemotherapy. There were no significant differences between patients' clinical and tumour-related characteristics in the two chemotherapy groups (Table 1 ).

The median number of CK-19 $(+)$ cells before adjuvant chemotherapy was 2.0 (range, 0.6-1115.0) and 1.5 (range, 
Table 1. Patients characteristics

\begin{tabular}{|c|c|c|c|c|c|}
\hline \multirow[b]{2}{*}{ Characteristics } & \multicolumn{2}{|c|}{$\begin{array}{c}\text { Taxane-free } \\
\text { regimen }\end{array}$} & \multicolumn{2}{|c|}{$\begin{array}{l}\text { Taxane-based } \\
\text { regimen }\end{array}$} & \multirow[b]{2}{*}{$P$-value } \\
\hline & $n$ & $\%$ & $n$ & $\%$ & \\
\hline Patients enrolled & 211 & & 334 & & \\
\hline \multicolumn{6}{|l|}{ Age, years } \\
\hline Median & 54 & & 53 & & \\
\hline Range & $30-75$ & & $26-76$ & & \\
\hline \multicolumn{6}{|c|}{ Tumour size, cm } \\
\hline $\mathrm{T} 1(\leqslant 2.0)$ & 73 & 34.6 & 114 & 34.1 & 0.955 \\
\hline T2 (2.1-5.0) & 120 & 56.9 & 189 & 56.6 & \\
\hline $\mathrm{T} 3(>5.0)$ & 18 & 8.5 & 31 & 9.3 & \\
\hline \multicolumn{6}{|l|}{ Lymph nodes } \\
\hline NO & 67 & 31.8 & 104 & 31.1 & 0.980 \\
\hline N1-3 & 78 & 37.0 & 123 & 36.8 & \\
\hline $\mathrm{N}>3$ & 66 & 31.3 & 107 & 32.0 & \\
\hline \multicolumn{6}{|l|}{ Histology grade } \\
\hline Grade I, II & 119 & 56.4 & 196 & 58.7 & 0.656 \\
\hline Grade III & 92 & 43.6 & 138 & 41.3 & \\
\hline \multicolumn{6}{|l|}{ ER } \\
\hline $\mathrm{ER}(-)$ & 64 & 30.3 & 112 & 35.5 & 1.000 \\
\hline $\mathrm{ER}(+)$ & 119 & 56.4 & 206 & 61.7 & \\
\hline Unknown & 28 & 13.3 & 16 & 4.8 & \\
\hline \multicolumn{6}{|l|}{ PgR } \\
\hline $\operatorname{PgR}(-)$ & 69 & 31.7 & 128 & 38.3 & 0.635 \\
\hline $\operatorname{PgR}(+)$ & 113 & 53.6 & 190 & 56.9 & \\
\hline Unknown & 29 & 13.7 & 16 & 4.8 & \\
\hline \multicolumn{6}{|l|}{ HER-2/neu } \\
\hline HER2 (-) & 179 & 84.8 & 294 & 88.0 & 0.325 \\
\hline HER2 $(+)$ & 27 & 12.8 & 33 & 9.9 & \\
\hline Unknown & 5 & 2.4 & 7 & 2.1 & \\
\hline \multicolumn{6}{|c|}{ CK-19 mRNA(+) cells before chemotherapy } \\
\hline Yes & 88 & 41.7 & 149 & 44.6 & 0.535 \\
\hline No & 123 & 58.3 & 185 & 55.4 & \\
\hline
\end{tabular}

0.6-897.0) MCF-7 equivalents $/ 5 \mu \mathrm{g}$ of total RNA for the taxanefree and taxane-based groups, respectively.

Effect of chemotherapy regimens on the elimination of CK-19 mRNA $(+)$ CTCs. The proportion of patients with detectable CK-19 $(+)$ cells was significantly decreased from $43.5 \%(n=237$ patients) before chemotherapy to $34.9 \%$ ( $n=190$ patients) after the completion of adjuvant chemotherapy (McNemar test, $P<0.001$ ). The reduction rate of CK-19 $(+)$ cells was significantly higher in patients treated with taxane-based than with taxane-free regimes (11.4\% and 4.3\%, respectively; $P=0.002$, data not shown). Regarding patients without detectable CK-19 $(+)$ CTCs before chemotherapy, $83.7 \%$ and $80.5 \%$ of those treated with a taxane-free and a taxane-based regimen, respectively, remained CK-19 negative after chemotherapy (Table $2 ; P=0.547$ ). On the contrary, for patients with detectable CK-19 $(+)$ cells before chemotherapy, $74(49.7 \%)$ and $29(33.0 \%)$ of those treated with a taxane-based and a taxane-free regimen turned negative after chemotherapy (Table 2; $P=0.015)$. Moreover, the median number of CK-19 $(+)$ cells before and after therapy was significantly decreased in both groups (taxane-based group: 1.5 and 0.6 MCF-7 equivalents/5 $\mu \mathrm{g}$ RNA, respectively $(P<0.00001)$; taxane-free group: 2.0 and $1.1 \mathrm{MCF}-7$ equivalents $/ 5 \mu \mathrm{g}$ RNA, respectively $(P=0.017)$, data not shown).

Detection of CK-19 mRNA-positive cells, chemotherapy regimens and clinical outcome

Disease recurrence and DFS. After a median follow-up period of 71.0 months (range, 4-147), 122 patients (22.4\%) developed a distant $(n=96 ; 78.7 \%)$ and/or a loco-regional $(n=26 ; 21.3 \%)$ recurrence. The incidence of clinical relapses was significantly higher among patients with detectable CK-19 $(+)$ CTCs after the completion of therapy $(33.2 \%$ and $16.6 \%$ relapse rate for patients with and without detectable CK-19 $(+)$ CTCs post-chemotherapy, respectively $(P<0.00001)$. The median DFS for the whole group of patients has not yet been reached; however, the relative risk of recurrence was significantly reduced in patients who were treated with taxane-based regimens $(\mathrm{RR}=0.68 ; P=0.035$, Figure 1$)$. In addition, the median DFS was significantly improved in the group of patients with detectable CK-19 mRNA $(+)$ cells who were treated with a taxane-based regimen compared with the patients who were treated with a taxane-free regimen (10-year DFS rate $61.3 \%$ and $47.8 \%$, respectively; $P=0.018$, Figure $2 \mathrm{~A}$ ). In contrast, for patients without detectable CK-19 mRNA $(+)$ cells before chemotherapy there was a slight but not significant difference in terms of DFS between the two cohorts (10-year DFS rate: $70.2 \%$ (taxane-free group) and $80.0 \%$ (taxane-based group) $P=0.481$, Figure 2B).

The effect of taxane-free and taxane-based regimens on the clinical outcome has been further investigated according to their effect on the CK-19 $(+)$ CTCs; for this purpose, the patients' clinical outcome was analysed according to their CTC status both before and after chemotherapy. The incidence of clinical relapses

Table 2. Detection of CK-19 mRNA-positive cells before and after adjuvant chemotherapy according to chemotherapy regimen

CK-19 mRNA status after chemotherapy

\begin{tabular}{|l|c|c|c|}
\hline $\begin{array}{l}\text { CK-19 mRNA status before } \\
\text { chemotherapy }\end{array}$ & Chemotherapy & CK-19 negative & CK-19 positive \\
\hline CK-19 negative & Taxane-free $(n=123)$ & $103(83.7 \%)$ & $20(16.3 \%)$ \\
& Taxane-based $(n=185)$ & $149(80.5 \%)$ & $36(19.5 \%)$ \\
\hline CK-19 positive & Taxane-free $(n=88)$ & $29(33.0 \%)$ & $59(67.0 \%)$ \\
& Taxane-based $(n=149)$ & $74(49.7 \%)$ & 0.015 \\
\hline
\end{tabular}


was $34.5 \%$ and $13.5 \%(P=0.025)$ in patients who turned negative after the completion of taxane-free and taxane-based adjuvant chemotherapy, respectively (Table 3 ). In the subgroup of patients who remained CK-19 mRNA $(+)$ after adjuvant chemotherapy, the incidence of clinical relapses was $50.6 \%$ (taxane-free group) and $20.7 \%$ (taxane-based group) $(P=0.00001)$. In these patients, the median DFS was 101 months (range, 7-131) and 86 months (range, 12-145) in patients treated with a taxane-based and a taxane-free regimen, respectively (HR: 1.8; 95\% CI: 1.016-3.341, $P=0.044$ ).

Although the nodal status has affected the DFS in the entire population (median DFS in N0, N1-3, and N>3 patients: 126,121 , and $89 \mathrm{mo}$, respectively; $P<0.000001$ ), there was no statistically significant difference in terms of DFS between patients who were treated with a taxane-free and a taxane-based regimen in each nodal group (median DFS: 121 and 131 months, respectively, for N0 patients $(P=0.131) ; 117$ and 122 months for N1-3 patients $(P=0.245)$, and 82 and 94 months for $N>3$ patients $(P=0.162)$, data not shown).

Disease-related mortality and OS. Seventy (12.8\%) patients have died as a result of disease progression during the follow-up period

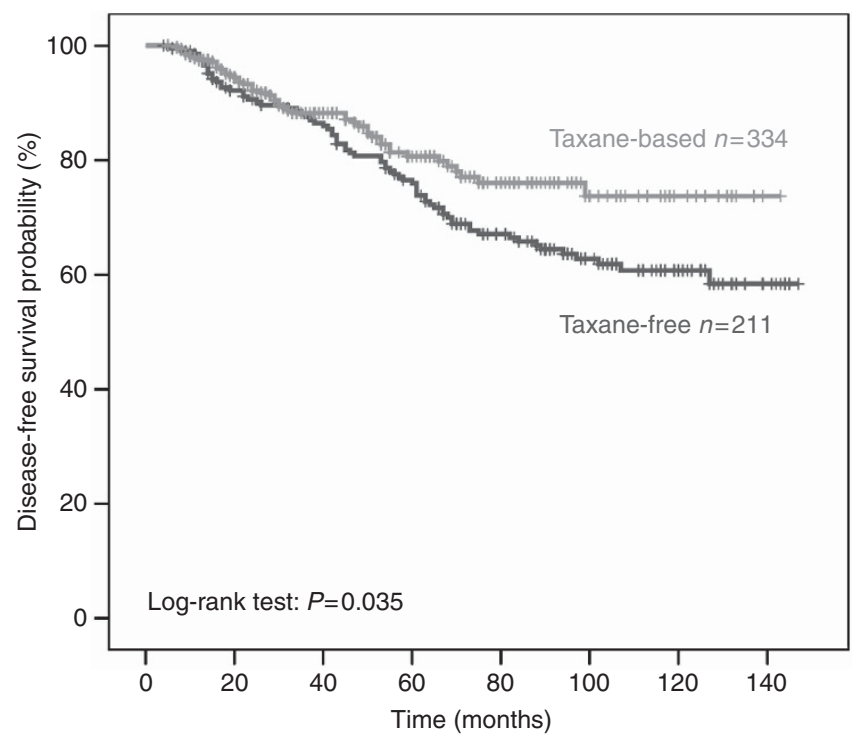

Figure 1. Disease-free survival according to chemotherapy regimen.

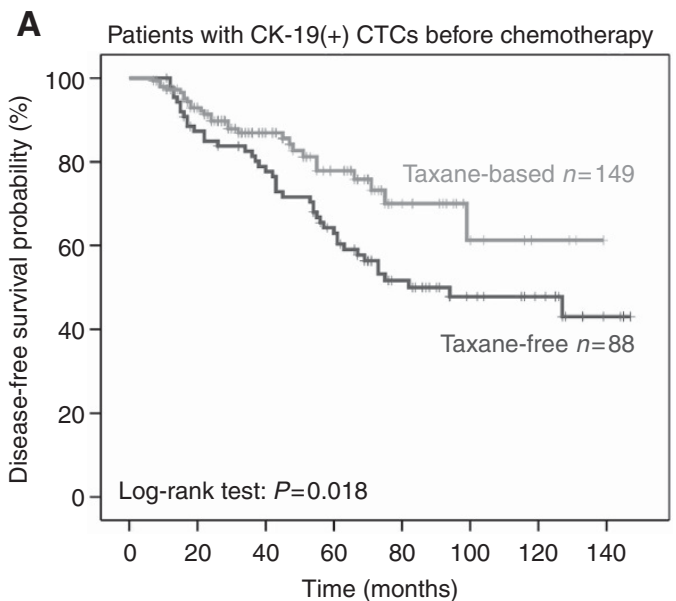

(taxane-free $(n=39 ; 55.7 \%)$ and taxane-based $(n=31 ; 44.3 \%)$; $P=0.002)$. The incidence of deaths was significantly higher in patients with detectable CK-19 mRNA $(+)$ CTCs before chemotherapy who received a taxane-free regimen compared with those who were treated with a taxane-based regimen $(29.5 \%$ and $12.1 \%$, respectively, $P=0.002$ ); however, there was no difference $(P=0.696)$ in terms of median OS between the two chemotherapy groups, irrespectively of the presence or the absence of CK-19 mRNA $(+)$ cells before chemotherapy (data not shown).

Univariate and multivariate analysis. Univariate analysis in the group of patients without detectable CTCs before chemotherapy revealed that tumour grade and lymph-node involvement, but not chemotherapy regimen, were significantly associated with reduced DFS and OS; multivariate analysis confirmed that the same parameters were independent predictors of disease recurrence and death (Table 4). In contrast, in the group of patients with detectable CK-19 $(+)$ CTCs before chemotherapy, all parameters (tumour size, grade, lymph-node involvement, hormone-receptor expression, and chemotherapy regimen) were significantly associated with disease recurrence in univariate. In multivariate analysis, all factors remained relevant for the disease relapse but tumour size $>2.0 \mathrm{~cm}$ and taxane-free regimens emerged as the strongest predictors of decreased DFS (HR: 2.03 and 2.00, respectively; Table 5). However, the interaction test between CK-19 (+) CTCs before chemotherapy and the treatment effect, according to the used regimen, was not significant $(P=0.31)$. Finally, multivariate analysis also revealed that tumour size, tumour grade, lymph-node involvement, and hormone receptor status emerged as independent factors associated with decreased OS.

\section{DISCUSSION}

In patients with locally advanced or metastatic breast cancer, treatment efficacy is evaluated by tumour shrinkage that seems to be associated with a prolonged progression-free survival and OS (Bruzzi et al, 2005). On the contrary, in patients with early stage breast cancer, the efficacy of adjuvant chemotherapy to eradicate the minimal residual disease (MRD) may be assessed only indirectly by the development of loco-regional or distant relapse and, more especially, the DFS. Therefore, until now the comparison of different adjuvant chemotherapy regimens is based only on the clinical outcome. However, several studies evaluating the value of CTCs after the completion of adjuvant chemotherapy,

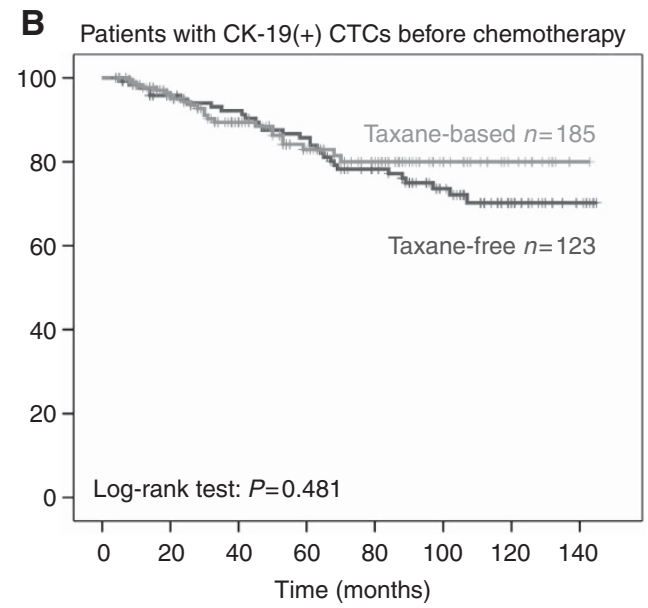

Figure 2. Disease-free survival according to chemotherapy regimen in patients with (A) and without (B) CK-19 mRNA-positive cells before chemotherapy. 
Table 3. Relapse rate (R), disease-free (DFS) and overall survival (OS) according to the detection of the CK-19 mRNA (+) CTCs before and after the completion of adjuvant chemotherapy and the type of chemotherapy

\begin{tabular}{|c|c|c|c|c|c|c|c|c|c|c|c|c|}
\hline & \multicolumn{3}{|c|}{$\begin{array}{c}\text { CK-19 pre }(-) / \\
\operatorname{post}(-)(n=252)\end{array}$} & \multicolumn{3}{|c|}{$\begin{array}{c}\text { CK-19 pre }(-) / \\
\operatorname{post}(+)(n=56)\end{array}$} & \multicolumn{3}{|c|}{$\begin{array}{c}\text { CK-19 pre }(+) / \\
\operatorname{post}(-)(n=103)\end{array}$} & \multicolumn{3}{|c|}{$\begin{array}{c}\text { CK-19 pre }(+) / \\
\operatorname{post}(+)(n=134)\end{array}$} \\
\hline Parameter & $\begin{array}{l}\mathrm{R} \\
(\%)\end{array}$ & $\begin{array}{c}\text { DFI } \\
\text { (months) }\end{array}$ & $\underset{\text { (months) }}{\text { OS }}$ & $\begin{array}{c}R \\
(\%)\end{array}$ & $\begin{array}{c}\text { DFI } \\
\text { (months) }\end{array}$ & $\begin{array}{c}\text { OS } \\
\text { (months) }\end{array}$ & $\begin{array}{l}R \\
(\%)\end{array}$ & $\begin{array}{c}\text { DFI } \\
\text { (months) }\end{array}$ & $\underset{\text { (months) }}{\text { OS }}$ & R (\%) & $\begin{array}{c}\text { DFI } \\
\text { (months) }\end{array}$ & $\underset{\text { (months) }}{\text { OS }}$ \\
\hline Taxane-free & 21.4 & 121 & 134 & 40.0 & 105 & 127 & 34.5 & 105 & 122 & 50.6 & 86 & 110 \\
\hline $\begin{array}{l}\text { Taxane- } \\
\text { based }\end{array}$ & 11.4 & 124 & 130 & 16.7 & 107 & 118 & 13.5 & 106 & 119 & 20.7 & 101 & 104 \\
\hline$P$-value & 0.035 & 0.569 & 0.602 & 0.105 & 0.623 & 0.996 & 0.025 & 0.451 & 0.682 & 0.0001 & 0.044 & 0.555 \\
\hline
\end{tabular}

Table 4. Univariate and multivariate analysis for disease recurrence and death from breast cancer in patients without detectable CK-19 mRNA ( + ) cells before chemotherapy

\begin{tabular}{|c|c|c|c|c|}
\hline & \multicolumn{2}{|c|}{ Univariate analysis } & \multicolumn{2}{|c|}{ Multivariate analysis } \\
\hline & HR $(95 \% \mathrm{Cl})$ & $P$-value & HR $(95 \% \mathrm{Cl})$ & $P$-value \\
\hline \multicolumn{5}{|l|}{ Disease-free survival } \\
\hline 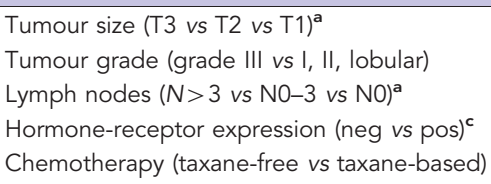 & $\begin{array}{l}1.30(0.84-2.01) \\
1.90(1.10-3.29) \\
2.37(1.60-3.51) \\
1.07(0.58-1.99) \\
1.22(0.70-2.11)\end{array}$ & $\begin{array}{r}0.235 \\
0.022 \\
<0.001 \\
0.822 \\
0.482\end{array}$ & $\begin{array}{c}\mathbf{- b}^{\mathbf{b}} \\
1.79(1.03-3.11) \\
2.34(1.57-3.49) \\
\mathbf{- b}^{\mathbf{b}} \\
\mathbf{b}^{\mathbf{b}}\end{array}$ & $\begin{array}{l}-^{\mathbf{b}} \\
0.038 \\
<0.001 \\
\mathbf{-}^{\mathbf{b}} \\
\mathbf{-}^{\mathbf{b}}\end{array}$ \\
\hline \multicolumn{5}{|l|}{ Overall survival } \\
\hline 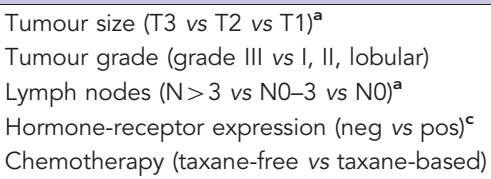 & $\begin{array}{l}1.74(0.93-3.26) \\
2.33(1.04-5.23) \\
3.08(1.66-5.71) \\
1.58(0.69-3.62) \\
1.22(0.56-2.65)\end{array}$ & $\begin{array}{r}0.084 \\
0.040 \\
<0.001 \\
0.276 \\
0.616\end{array}$ & $\begin{array}{c}\text { - }^{\mathbf{b}} \\
2.23(1.00-5.01) \\
3.07(1.65-5.75) \\
\mathbf{C}^{\mathbf{b}} \\
\mathbf{C}^{\mathbf{b}}\end{array}$ & $\begin{array}{l}-^{\mathbf{b}} \\
0.051 \\
<0.001 \\
-^{\mathbf{b}} \\
-^{\mathbf{b}}\end{array}$ \\
\hline \multicolumn{5}{|c|}{ 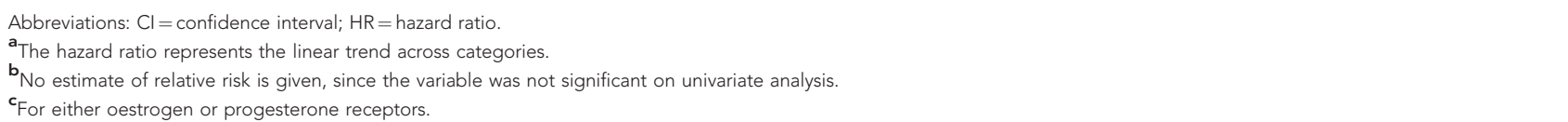 } \\
\hline
\end{tabular}

as a marker of disease relapse, demonstrated that their persistence (Quintela-Fandino et al, 2006; Rack et al, 2008; Xenidis et al, 2009) or increased number (Pachmann et al, 2008) is associated with poor prognosis, suggesting the failure of adjuvant treatment to eradicate MRD.

To the best of our knowledge, this is the first report comparing the effect of two chemotherapy regimens (taxane-based and taxane-free) on CTCs in patients with early stage breast cancer and correlates this effect with patients' clinical outcome. Although this is a retrospective analysis of data from two non-randomised cohorts of patients, the results indicate that both regimens could significantly eliminate CK-19 $(+)$ cells but the effect of taxanebased regimens was more pronounced than that of taxane-free combinations (Table 2; $P=0.015$ ). This observation should be attributed to the incorporation of taxanes (both docetaxel and paclitaxel), which was the main difference between the two regimens; whether this effect represents a greater sensitivity of CTCs to taxanes or it is an additive effect of the chemotherapy agents is unknown. This observation is in agreement with several recent clinical data indicating the superiority of taxane-containing regimens in the adjuvant setting and could be explained by the fact that incorporation of taxanes in the adjuvant treatment is more pronounced in patients with HER2-positive tumours (Hayes et al,
2007; Ellis et al, 2009). Several studies have shown that CTCs express HER2/c-neu (Wulfing et al, 2010) irrespectively of the HER2 status of the primary tumours (Pestrin et al, 2009). This discrepancy could be due to HER2/c-neu amplification in CTCs, acquired during the migration process of the tumour cells (Meng et al, 2004) or to a clone selection in an HER2-negative primary tumour. Therefore, we cannot exclude the hypothesis that the observed higher efficacy of taxane-based regimens could be attributed to the effect of taxanes on HER2 $(+)$ CTCs.

In the current study, the median DFS was significantly improved in patients treated with a taxane-based regimen. This observation is in agreement with the results of recent metaanalyses, indicating that taxane-based adjuvant chemotherapy provides an improvement in DFS when compared with standard anthracycline-based chemotherapy (Bria et al, 2006; Ferguson et al, 2007; De Laurentiis et al, 2008). Since patients without detectable CK-19 (+ ) CTCs showed almost identical DFS, irrespectively of the administered chemotherapy regimen, it is reasonable to hypothesise that the observed beneficial effect of a taxane-based regimen on DFS may be attributed to its effect on the subgroup of patients with detectable CK-19 (+) CTCs. Indeed, in this particular group of patients, the administration of a taxane-based chemotherapy regimen improved substantially the DFS and 


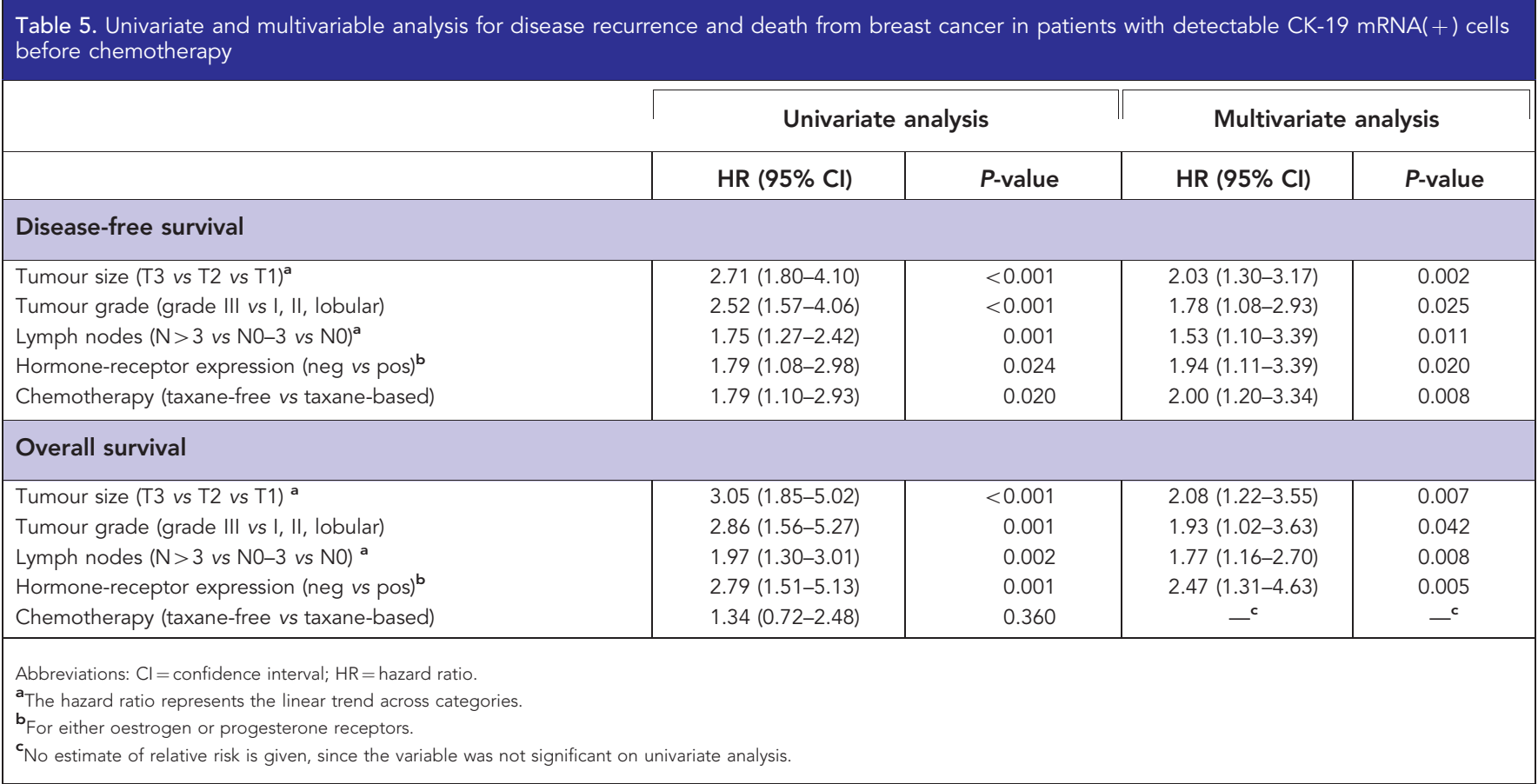

decreased significantly the probability of relapse compared with patients treated with a taxane-free regimen. Moreover, multivariate analysis in this subgroup of patients clearly revealed that treatment with a taxane-free chemotherapy regimen was an independent factor associated with an increased risk of early disease recurrence. However, no definitive conclusions concerning the DFS can be drawn from these results since the interaction test between CK-19 $(+)$ CTCs before chemotherapy and the treatment effect, according to the used regimen, was not significant; this could be attributed to the low and different number of patients between the two groups. Nevertheless, we propose that the benefit of patients treated with a taxane-based regimen in terms of DFS and disease relapse rate should be due to a more effective elimination of CK19(+) CTCs due to the administration of taxanes. This hypothesis is mainly supported by the observation that taxane-based chemotherapy was associated with a significantly higher DFS compared with taxane-free regimens in the subgroup of patients who had detectable CK-19 (+) CTCs both before and after the completion of adjuvant chemotherapy, in agreement with our previous report (Xenidis et al, 2009). Conversely, there was no difference in terms of DFS in the other subgroups of patients according to the detection of CK-19 $(+)$ CTCs before and after adjuvant chemotherapy, irrespectively of the administered chemotherapy regimen (data not shown). However, the observational, retrospective, and non-randomised nature of the trial are important limiting factors of this analysis; therefore, these observations should be considered with caution.

In the current study, there was no difference in terms of median OS between the two chemotherapy regimens, irrespectively of the detection of CK-19 (+) CTCs cells before chemotherapy; however, there were more disease-related deaths among patients treated with a taxane-free regimen compared with patients who were treated with a taxane-based regimen. Although administration of a taxane-based chemotherapy regimen improved substantially the DFS and even if there were more disease-related deaths among patients treated with a taxane-free regimen compared with patients who were treated with a taxane-based regimen, there was no difference in terms of median OS between the two chemotherapy regimens, irrespectively of the detection of
CK-19 (+) CTCs cells before chemotherapy. This discrepancy could related to the fact that relapsed patients after the administration of an adjuvant taxane-free regimen still have the opportunity to receive salvage taxane-based chemotherapy which might have a beneficial effect on survival; alternatively, we cannot exclude that other factors (i.e., insufficient number of patients in each group of patients or/and follow-up time) could account for this observation.

Previous studies have shown that the detection of CTCs before chemotherapy in patients with early breast cancer is the most important independent factor associated with an increased incidence of disease relapse and disease-related death (Ignatiadis et al, 2007; Apostolaki et al, 2009). Similar findings concerning the prognostic value of CTCs (Masuda et al, 2005; Bidard et al, 2010) and DTCs (Braun et al, 2005) have been described by other investigators using different techniques for the detection of CTCs. In the current study, multivariate analysis performed in all patients demonstrated that both the detection of CK-19 $(+)$ CTCs before chemotherapy and the administration of a taxane-free regimen could emerged as independent factors associated with a poor DFS in agreement with the above-mentioned data (Braun et al, 2005; Masuda et al, 2005; Ignatiadis et al, 2007; Bidard et al, 2010). Therefore, based on these data, the addition of a taxane to an anthracycline-based regimen in patients with detectable CK-19 $(+)$ CTCs seems a reasonable therapeutic approach since it may more efficiently eradicate CTCs improving, thus, the DFS. Consequently, the determination of CTCs status before the initiation of adjuvant chemotherapy in patients with early stage breast cancer could identify patients who are likely to derive a significant benefit from the addition of a taxane in the adjuvant chemotherapy regimen. However, this hypothesis should be evaluated in appropriately designed prospective trials. Moreover, enumeration of CTCs before and after the completion of chemotherapy could be a crucial stratification factor for the design of studies in the adjuvant setting and a useful tool for the early evaluation of effectiveness of the adjuvant chemotherapy. For the time being the detection of CK-19 $(+)$ CTCs as a marker for therapeutic decision making in patients with early breast cancer should be considered investigational and used only in the context of clinical trials. 


\section{ACKNOWLEDGEMENTS}

This work was partly supported by research grants from the Cretan Association for Biomedical Research (CABR) and the Hellenic Society of Medical Oncology (HeSMO).

\section{CONFLICT OF INTEREST}

The authors declare no conflict of interest.

REFERENCES

Apostolaki S, Perraki M, Kallergi G, Kafousi M, Papadopoulos S, Kotsakis A, Pallis A, Xenidis N, Kalmanti L, Kalbakis K, Agelaki S, Kalykaki A, Stournaras C, Stathopoulos E, Georgoulias V, Mavroudis D (2009) Detection of occult HER2 mRNA-positive tumor cells in the peripheral blood of patients with operable breast cancer: evaluation of their prognostic relevance. Breast Cancer Res Treat 117(3): 525-534.

Bidard FC, Mathiot C, Delaloge S, Brain E, Giachetti S, de CP, Marty M, Pierga JY (2010) Single circulating tumor cell detection and overall survival in nonmetastatic breast cancer. Ann Oncol 21(4): 729-733.

Bonadonna G, Moliterni A, Zambetti M, Daidone MG, Pilotti S, Gianni L, Valagussa P (2005) 30 years' follow up of randomised studies of adjuvant CMF in operable breast cancer: cohort study. BMJ 330(7485): 217.

Bozionellou V, Mavroudis D, Perraki M, Papadopoulos S, Apostolaki S, Stathopoulos E, Stathopoulou A, Lianidou E, Georgoulias V (2004) Trastuzumab administration can effectively target chemotherapy-resistant cytokeratin-19 messenger RNA-positive tumor cells in the peripheral blood and bone marrow of patients with breast cancer. Clin Cancer Res 10(24): 8185-8194.

Braun S, Vogl FD, Naume B, Janni W, Osborne MP, Coombes RC, Schlimok G, Diel IJ, Gerber B, Gebauer G, Pierga JY, Marth C, Oruzio D, Wiedswang G, Solomayer EF, Kundt G, Strobl B, Fehm T, Wong GY, Bliss J, Vincent-Salomon A, Pantel K (2005) A pooled analysis of bone marrow micrometastasis in breast cancer. N Engl J Med 353(8): 793-802.

Bria E, Nistico C, Cuppone F, Carlini P, Ciccarese M, Milella M, Natoli G, Terzoli E, Cognetti F, Giannarelli D (2006) Benefit of taxanes as adjuvant chemotherapy for early breast cancer: pooled analysis of 15,500 patients. Cancer 106(11): 2337-2344.

Bruzzi P, Del ML, Sormani MP, Bastholt L, Danova M, Focan C, Fountzilas G, Paul J, Rosso R, Venturini M (2005) Objective response to chemotherapy as a potential surrogate end point of survival in metastatic breast cancer patients. J Clin Oncol 23(22): 5117-5125.

Budd GT, Cristofanilli M, Ellis MJ, Stopeck A, Borden E, Miller MC, Matera J, Repollet M, Doyle GV, Terstappen LW, Hayes DF (2006) Circulating tumor cells $v s$ imaging-predicting overall survival in metastatic breast cancer. Clin Cancer Res 12(21): 6403-6409.

Camara O, Rengsberger M, Egbe A, Koch A, Gajda M, Hammer U, Jorke C, Rabenstein C, Untch M, Pachmann K (2007) The relevance of circulating epithelial tumor cells (CETC) for therapy monitoring during neoadjuvant (primary systemic) chemotherapy in breast cancer. Ann Oncol 18(9): 1484-1492.

Cristofanilli M, Budd GT, Ellis MJ, Stopeck A, Matera J, Miller MC, Reuben JM, Doyle GV, Allard WJ, Terstappen LW, Hayes DF (2004) Circulating tumor cells, disease progression, and survival in metastatic breast cancer. N Engl J Med 351(8): 781-791.

De Laurentiis M, Cancello G, D'Agostino D, Giuliano M, Giordano A, Montagna E, Lauria R, Forestieri V, Esposito A, Silvestro L, Pennacchio R, Criscitiello C, Montanino A, Limite G, Bianco AR, De PS (2008) Taxanebased combinations as adjuvant chemotherapy of early breast cancer: a meta-analysis of randomized trials. J Clin Oncol 26(1): 44-53.

Early Breast Cancer Trialists' Collaborative Group (2005) Effects of chemotherapy and hormonal therapy for early breast cancer on recurrence and 15-year survival: an overview of the randomised trials. Lancet 365(9472): 1687-1717.

Ellis P, Barrett-Lee P, Johnson L, Cameron D, Wardley A, O'Reilly S, Verrill M, Smith I, Yarnold J, Coleman R, Earl H, Canney P, Twelves C, Poole C, Bloomfield D, Hopwood P, Johnston S, Dowsett M, Bartlett JM, Ellis I, Peckitt C, Hall E, Bliss JM (2009) Sequential docetaxel as adjuvant chemotherapy for early breast cancer (TACT): an open-label, phase III, randomised controlled trial. Lancet 373(9676): 1681-1692.

Ferguson T, Wilcken N, Vagg R, Ghersi D, Nowak AK (2007) Taxanes for adjuvant treatment of early breast cancer. Cochrane Database Syst Rev 4: CD004421.

Hayes DF, Cristofanilli M, Budd GT, Ellis MJ, Stopeck A, Miller MC, Matera J, Allard WJ, Doyle GV, Terstappen LW (2006) Circulating tumor cells at each follow-up time point during therapy of metastatic breast cancer patients predict progression-free and overall survival. Clin Cancer Res 12(14 Part 1): 4218-4224.

Hayes DF, Thor AD, Dressler LG, Weaver D, Edgerton S, Cowan D, Broadwater G, Goldstein LJ, Martino S, Ingle JN, Henderson IC, Norton L, Winer EP, Hudis CA, Ellis MJ, Berry DA (2007) HER2 and response to paclitaxel in node-positive breast cancer. N Engl J Med 357(15): 1496-1506.

Ignatiadis M, Xenidis N, Perraki M, Apostolaki S, Politaki E, Kafousi M, Stathopoulos EN, Stathopoulou A, Lianidou E, Chlouverakis G, Sotiriou C, Georgoulias V, Mavroudis D (2007) Different prognostic value of cytokeratin-19 mRNA positive circulating tumor cells according to estrogen receptor and HER2 status in early-stage breast cancer. J Clin Oncol 25(33): 5194-5202.

Liu MC, Shields PG, Warren RD, Cohen P, Wilkinson M, Ottaviano YL, Rao SB, Eng-Wong J, Seillier-Moiseiwitsch F, Noone AM, Isaacs C (2009) Circulating tumor cells: a useful predictor of treatment efficacy in metastatic breast cancer. J Clin Oncol 27(31): 5153-5159.

Masuda TA, Kataoka A, Ohno S, Murakami S, Mimori K, Utsunomiya T, Inoue H, Tsutsui S, Kinoshita J, Masuda N, Moriyama N, Mori M (2005) Detection of occult cancer cells in peripheral blood and bone marrow by quantitative RT-PCR assay for cytokeratin-7 in breast cancer patients. Int $J$ Oncol 26(3): 721-730.

McShane LM, Altman DG, Sauerbrei W, Taube SE, Gion M, Clark GM (2005) Reporting recommendations for tumor marker prognostic studies (REMARK). J Natl Cancer Inst 97(16): 1180-1184.

Meng S, Tripathy D, Shete S, Ashfaq R, Haley B, Perkins S, Beitsch P, Khan A, Euhus D, Osborne C, Frenkel E, Hoover S, Leitch M, Clifford E, Vitetta E, Morrison L, Herlyn D, Terstappen LW, Fleming T, Fehm T, Tucker T, Lane N, Wang J, Uhr J (2004) HER-2 gene amplification can be acquired as breast cancer progresses. Proc Natl Acad Sci USA 101(25): 9393-9398.

Pachmann K, Camara O, Kavallaris A, Krauspe S, Malarski N, Gajda M, Kroll T, Jorke C, Hammer U, Altendorf-Hofmann A, Rabenstein C, Pachmann U, Runnebaum I, Hoffken K (2008) Monitoring the response of circulating epithelial tumor cells to adjuvant chemotherapy in breast cancer allows detection of patients at risk of early relapse. J Clin Oncol 26(8): 1208-1215.

Pestrin M, Bessi S, Galardi F, Truglia M, Biggeri A, Biagioni C, Cappadona S, Biganzoli L, Giannini A, Di LA (2009) Correlation of HER2 status between primary tumors and corresponding circulating tumor cells in advanced breast cancer patients. Breast Cancer Res Treat 118(3): 523-530.

Pierga JY, Bidard FC, Mathiot C, Brain E, Delaloge S, Giachetti S, de CP, Salmon R, Vincent-Salomon A, Marty M (2008) Circulating tumor cell detection predicts early metastatic relapse after neoadjuvant chemotherapy in large operable and locally advanced breast cancer in a phase II randomized trial. Clin Cancer Res 14(21): 7004-7010.

Polyzos A, Malamos N, Boukovinas I, Adamou A, Ziras N, Kalbakis K, Kakolyris S, Syrigos K, Papakotoulas P, Kouroussis C, Karvounis N, Vamvakas L, Christophyllakis C, Athanasiadis A, Varthalitis I, Georgoulias V, Mavroudis D (2010) FEC versus sequential docetaxel followed by epirubicin/cyclophosphamide as adjuvant chemotherapy in women with axillary node-positive early breast cancer: a randomized study of the Hellenic Oncology Research Group (HORG). Breast Cancer Res Treat 119(1): 95-104.

Quintela-Fandino M, Lopez JM, Hitt R, Gamarra S, Jimeno A, Ayala R, Hornedo J, Guzman C, Gilsanz F, Cortes-Funes H (2006) Breast cancerspecific mRNA transcripts presence in peripheral blood after adjuvant chemotherapy predicts poor survival among high-risk breast cancer patients treated with high-dose chemotherapy with peripheral blood stem cell support. J Clin Oncol 24(22): 3611-3618.

Rack B, Schindlbeck C, Schneeweiss A (2008) Prognostic relevance of circulating tumor cells (CTCs) in peripheral blood of breast cancer patients before and after adjuvant chemotherapy: The German SUCCESS-Trial. Abstract \#503 presented at ASCO. 
Stathopoulou A, Gizi A, Perraki M, Apostolaki S, Malamos N, Mavroudis D, Georgoulias V, Lianidou ES (2003) Real-time quantification of CK-19 mRNA-positive cells in peripheral blood of breast cancer patients using the lightcycler system. Clin Cancer Res 9(14): 5145-5151.

Wulfing P, Brochard J, Buerger H, Heidl S, Zanker KS, Kiesel L, Brandt B (2010) HER2 positive circulating tumor cells indicate poor clinical outcome in stage I to III breast cancer patients. Clin Cancer Res 12: $1715-1720$

Xenidis N, Ignatiadis M, Apostolaki S, Perraki M, Kalbakis K, Agelaki S, Stathopoulos EN, Chlouverakis G, Lianidou E, Kakolyris S, Georgoulias V,
Mavroudis D (2009) Cytokeratin-19 mRNA-positive circulating tumor cells after adjuvant chemotherapy in patients with early breast cancer. $J$ Clin Oncol 27(13): 2177-2184.

This work is published under the standard license to publish agreement. After 12 months the work will become freely available and the license terms will switch to a Creative Commons AttributionNonCommercial-Share Alike 3.0 Unported License. 